\title{
Research on Spatial Agglomeration of Real Estate Investment in China
}

\author{
Youyang You \\ International Business School \\ Yunnan university of Finance and Economics \\ Kunming, China \\ 85621767@qq.com
}

\begin{abstract}
In this paper, Linear Footloose Capital Model (LFC Model) is used to explain the spatial agglomeration principle of real estate investment, and regional return on capital determines the direction of real estate investment, while the rate of return on capital is influenced by combined action of both market scale effect and market crowding-out effect. In this paper, Spatial Dubin Model (SDM) is built by considering such four factors as urban size, related element (manufacturing scale), per capita income and market potential and based on the data of 259 cities at and above prefecture level in China from 2003 to 2014. The results show that each factor has significant positive effect on real estate investment, while the spatial lag items of urban size and market potential have significant negative impact on real estate investment, indicating that when urban size and market potential grow to a certain extent, the intensity of market competition increases and the crowding-out effect on real estate investment is dominant, causing real estate investment to flow out from big cities.
\end{abstract}

Keywords-real estate development investment; footloose capital model; rate of return on capital; spatial dubin model

\section{INTRODUCTION}

Since the 18th National Congress of the CPC, new-type urbanization has developed rapidly in China. As the material basis for the development of new-type urbanization, the real estate industry has played an important role in the course of promoting the development of new-type urbanization and national economy in China. Since the real estate industry has the characteristics of long industrial chain and obvious driving effect, its changes usually have a great impact on many related industries, which in return affects the stable and coordinated development of macro economy. In recent years, the contribution of the real estate industry to GDP has been around $10 \%$, pulling GDP growth by about 1.5 to 2 percentage points per year. In 2000, the investment amount of real estate industry in China was 498.4 billion yuan, while in 2015, this figure increased to 9.5979 trillion yuan, 19 times that of 2000; accordingly, the proportion of real estate development investment in total fixed asset investment increased from $15.1 \%$ in 2000 to $19.8 \%$ in 2011 ; in recent years, the proportion of real estate investment has been relatively stable. As of 2015, the proportion of real estate development investment in total fixed asset investment accounted for $17.1 \%$.

The rapid development of the real estate industry as a whole makes people ignore the differences in geographical space, and few scholars have carried out concrete research on the spatial development conditions of the real estate industry. The market-oriented reform has eliminated market segmentation among different regions in China and accelerated the flow of production factors and labor products among different regions, as a result, the efficiency of resource allocation has been improved, and the spatial agglomeration of economic activities has become a common phenomenon in the process of economic development.

\section{LITERATURE REVIEW}

The literature related to this paper mainly involves two aspects, one is the research literature on industrial agglomeration, the other is the research literature on real estate economy in China.

\section{A. Research on Industrial Agglomeration}

The research on industrial spatial agglomeration can be traced back to 1890 when Marshall [1] discussed the reasons for the agglomeration development of enterprises, which can be summarized as three points: one is to be close to customers and suppliers; the second is to share labor market; and the third is knowledge and technology spillover. An in-depth theoretical study on agglomeration phenomenon was carried out by Krugman [2] based on Dixit and Stiglitz's Monopolistic Competition Model (1977), he considered that the flow and agglomeration of capital and population will expand the final consumer goods market and intermediate input product market in the agglomeration area, reduce the cost of manufacturers and obtain economies of scale, and moreover, agglomeration economy has self-reinforcing effect. In the course of studying competitive advantage of a country, Porter [4]put forward his famous "Diamond Model" regarding regional competitiveness, he emphasized the role of industrial agglomeration in the international competitiveness of regional industries and believed that industrial agglomeration could promote regional competition and maintain or increase its economic growth rate. Helpman [5] constructed a theoretical model under which agricultural sector is replaced with urban land and housing. The results show that when interval transaction cost is higher than indoor congestion cost, the agglomeration is stable and balanced. Puga [6] believed that the rise of labor costs will make enterprises reweigh agglomeration benefits gained in big cities and low-cost labor force available in other cities. Ottaviano et al. [7] introduced non-mobile sectors and urban commuting costs to

*Corresponding author 
build a theoretical model, under which it is found that under the joint action of multiple forces, as transaction costs gradually fall from high levels, spatial equilibrium presents the law of change from dispersion to agglomeration and then to dispersion.

In recent years, domestic and foreign scholars have empirically quantified industrial agglomeration and urban economic population agglomeration by calculating location entropy, spatial Gini coefficient and industrial agglomeration index, etc. Wen Mei [8] studied the degree of industrial concentration in China from 1980 to 1995, she believed that since the reform and opening up, China's manufacturing industry has become more and more geographically concentrated, the decline in transportation expenses may facilitate further agglomeration of the manufacturing industry, which supports new economic geography theory. By applying EG index (y index) constructed by Ellison and Glaeser [9], Wen Dongwei and Xian Guoming [10] quantified the spatial agglomeration degree of China's manufacturing industry, the results show that the spatial agglomeration degree of China's manufacturing industry is obviously deepening, and more and more manufacturing industries are increasingly concentrated in a limited number of provinces or districts and counties along the eastern coast. He Canfei et al. [11] studied the industrial distribution of China's manufacturing industry from different geographical scales and found that the manufacturing industry in China is highly concentrated, and the smaller the spatial scale is, the more concentrated the manufacturing industry is in space. Luo Yong \& Cao Lili [12] made a research on the agglomeration degree of manufacturing industry from its different types (technology-intensive, capital-intensive and labor-intensive). The results show that the agglomeration degree of technology-intensive type is the highest, while that of labor-intensive type is the lowest. On the whole, there is a strong positive correlation between the agglomeration degree of a manufacturing industry and its industrial growth. Chen Jianjun et al. [13] explored the causes and development trend of the agglomeration of producer services in China by constructing a theoretical framework for the agglomeration of producer services. Xu Xiaoguang et al. [14] studied the spillover effect of financial agglomeration on the economic transformation of special economic zones by taking Shenzhen Special Economic Zone as an example. Some scholars studied the effect of agglomeration externality on economic development from the perspective of the role of industrial agglomeration and economic agglomeration in improving labor productivity and economic efficiency of enterprises [15][16].

\section{B. Research on Real Estate Economy}

The real estate industry is an important industry in the national economy. From the perspective of the relationship between supply and demand of the industries, the effects of the real estate industry on its related industries are mainly forward correlation effect and backward correlation effect. Therefore, many scholars applied the input-output model used for national economic accounting to study the driving effect of the real estate industry on its related industries and on macro economy [17][18][19]. Zhou Jingkui and Wu Xiaoyan [20]studied the dynamic influencing mechanism of different types of real estate markets on regional economic growth as well as the effect of regional economic growth on real estate price by constructing the relational model between real estate and regional economic growth. By comparing the differences in the effect of real estate price on regional economy under demand shock and supply shock respectively, it is found that there is a reverse relationship between real estate price and industrial added value. Zhou Zhichun et al. [21] applied multivariable VAR model to carry out research on the interaction between real estate cycle and economic cycle in China, the findings show that the real estate industry influences the periodic fluctuation of national economy through the periodic fluctuations of industry correlation effect, financial stability effect and asset price effect; while the periodic fluctuation of national economy influences the periodic fluctuation of real estate industry through output effect, monetary policy effect, income effect and urbanization effect, and the response of macro economy to real estate investment is relatively slow. Gao Bo et al. [22], Chen Jian and Zou Linhua [23] expanded the New Economic Geography Model and introduced housing price factor. It is found that the difference in regional house prices leads to the flow of labor force. When relative house price rises, it will lead to higher cost of living and lower consumer utility, thus reducing the inflow of workers and affecting the industrial transfer and industrial upgrading in the eastern, central and western parts of China.

The importance of real estate to the economy is mainly reflected by investment. There have been many studies on the relationship between real estate investment and macro economy. Huang Zhonghua et al. [24] analyzed the impact of real estate investment on economic growth in China from 1997 to 2006 and found that the impact of real estate investment on the economy depends on the level of regional economic development. Chen Shuyun and Fu Zhenqi [25] used multi-index panel data to classify 70 large and medium-sized cities in China and based on this, studied the power of real estate investment to drive the economy of cities of different sizes. The spatial spillover effect of real estate investment on different regions in China was analyzed by Zhang Hong and Quan Shifan et al. [26] using spatial dynamic panel data (SDPD) method. By applying the theoretical method of national economic accounting, $\mathrm{Xu}$ Xianchun and Jia Hai et al. [27] conducted a complete quantitative analysis of the effect of real estate on the growth of China's national economy from three major fields of real estate development investment, real estate production and real estate consumption. Research shows that the real estate economy should maintain a reasonable growth in order to effectively promote the healthy and stable development of the national economy. Wang Chongrun and Cui Yinsheng [28] built real estate investment effect model and the economic growth model of real estate investment crowding-out effect from the angle of real estate investment crowding-out effect to study the effect of real estate investment on economic growth of the regions with different levels of development in China.

\section{MODEL SPECIFICATION AND URBAN INDICATORS}

According to the theoretical analysis, the flow of real estate development investment is determined by the rate of return on capital, and regional return on capital is affected by transaction costs, besides, such factors as the degree of poverty in the region, urban size, related elements and market potential also affect the rate of return on capital. Spatial Dubin Model (SDM) is built by using the data of 259 cities at and above prefecture level across the country from 2003 to 2014 (with the main source of data from each year's CHINA CITY STATISTICAL YEARBOOK and CEInet Statistics Database) and taking into account regional economic spillover and intercity interaction effect: 


$$
\begin{aligned}
\operatorname{Inin} v_{i, t}=\rho \text { Inin }_{i, t} & \\
& +\beta_{j}\left(\text { Incit }_{i, t}+\text { Inman }_{i, t}+\text { Inper }_{i, t}\right. \\
& \left.+ \text { Inmar }_{i, t}\right) \\
& +\theta_{j} \text { W }_{\text {Incit }_{i, t}}+\text { Inman }_{i, t}+\text { Inper }_{i, t} \\
& \left.+ \text { Inmar }_{i, t}\right)+\varepsilon_{i, t} \quad j=1,2,3,4
\end{aligned}
$$

Of which, the subscript i represents prefecture-level region, the subscript $t$ represents the year. Because of the obvious exponential effect of each variable in time trend, the logarithm of each variable is therefore taken. Ininv $v_{i, t}$ Represents the explained variable - real estate development investment; Incit $_{\mathrm{i}, \mathrm{t}}$ represents urban size; Inman $_{\mathrm{i}, \mathrm{t}}$ represents related element; Inper $_{i, t}$ represents per capita income level; Inmar $_{i, t}$ represent market potential; $\mathrm{W}$ represents spatial weight matrix, and in this paper, the reciprocal of Euclidean distance between cities is chosen as the weight; $\varepsilon_{\mathrm{i}, \mathrm{t}}$ represents error term.

In this paper, real estate development investment inv is the explained variable, which is measured by the amount of Investment completed by urban real estate enterprises, and urban size cit is expressed by the number of the city's population at the end of the year. Since the development of the real estate industry is closely related to that of the manufacturing industry, the related element man is expressed by the employed population of urban manufacturing industry, people's purchasing power affects the demand level of the real estate market, so the average salary of the employed population in cities and towns is taken as a factor affecting real estate investment. In this paper, Harris [29]'s measurement method is adopted to measure the market potential of each prefecture-level city, the calculation formula is as follows: $\mathrm{MP}_{\mathrm{r}}=\sum_{\mathrm{r} \neq \mathrm{j}} \frac{\mathrm{Y}_{\mathrm{j}}}{\mathrm{d}_{\mathrm{rj}}}+\frac{\mathrm{Y}_{\mathrm{r}}}{\mathrm{d}_{\mathrm{rr}}}$, of which, Y represents urban GRP, in this paper, the year 2003 is taken as the base year and Y is deflated by the GDP deflator of the province to which each prefecture-level city belongs; $\mathrm{d}_{\mathrm{rj}}$ represents Euclidean distance between the administrative centers of prefecture-level cities; $d_{r r}$ represents the internal distance of each prefecture-level city. Of which, area indicates the land area within the jurisdiction of each prefecture-level city.

\section{ECONOMIC ANALYSIS ON THE INFLUENCING FACTORS OF REAL ESTATE INVESTMENT AGGLOMERATION MECHANISM}

\section{A. General Panel Data Regression}

In this part, random effect model (RE), fixed effect model (FE) and generalized least squares estimation are used to estimate the general panel model. Table 1 reports the regression results of these three models.

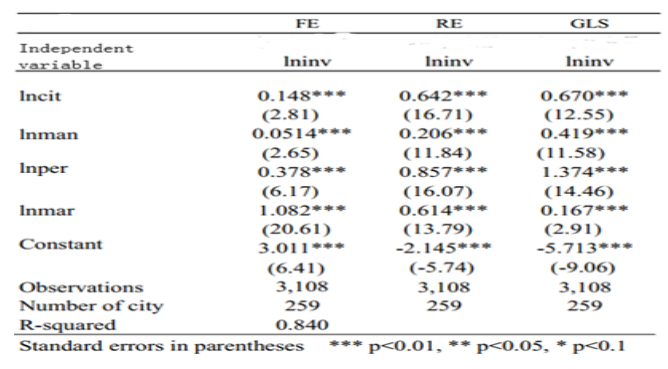

Fig. 1. Regression Result of Panel Data
Hausman test is carried out to random effect model, the original hypothesis of the model is not rejected, RE model fits well the relation between the explanatory variable and the explained variable. Assuming there is heteroscedasticity between the data of different cities, the generalized least squares estimation method is adopted to fit the model, and the result is similar to random effect model, with even smaller error. The estimation results of RE model and GLS model are highly consistent with the theoretical expectations. The parameter estimations of urban size, manufacturing elements, per capita income level and market potential are all significantly positive at $1 \%$ significance level, which means that on the whole, all factors have positive attraction to China's real estate investment.

\section{B. Regression results of Spatial Panel Model}

Based on the influence of various factors on the spatial flow of real estate investment, this paper chooses Spatial Dubin Model (SDM) to carry out regression estimation. Since SDM contains the lag term of the explained variable, using OLS

\begin{tabular}{|c|c|c|c|c|}
\hline VARIABLES & $\begin{array}{l}\text { (1) } \\
\text { Main }\end{array}$ & $\begin{array}{l}\text { (2) } \\
W_{x}\end{array}$ & $\begin{array}{c}\text { (3) } \\
\text { Spatial }\end{array}$ & $\begin{array}{c}(4) \\
\text { Variance }\end{array}$ \\
\hline Incit & $\begin{array}{c}0.529 \cdots * * \\
(5.43)\end{array}$ & $\begin{array}{c}-1.636 * * \\
(-1.44)\end{array}$ & & \\
\hline Inman & $0.158^{\circ \cdots}$ & -0.0879 & & \\
\hline Inper & $\begin{array}{c}(3.92) \\
0.641 \cdots * \\
(4.09)\end{array}$ & $\begin{array}{c}(-0.704) \\
0.141 \\
(0.136)\end{array}$ & & \\
\hline Inmar & $\begin{array}{c}0.771^{* * *} \\
(0.86)\end{array}$ & $\begin{array}{c}-1.006 * * * * \\
(-1.011)\end{array}$ & & \\
\hline rho & & & $\begin{array}{l}0.843 * * * \\
(9.63)\end{array}$ & \\
\hline lgt_theta & & & & $\begin{array}{r}-1.779 * * * \\
(-0.134)\end{array}$ \\
\hline sigma2_e & & & & $\begin{array}{l}0.131^{* * *} \\
(0.00966)\end{array}$ \\
\hline Constant & $\begin{array}{l}0.0360 \\
(1.121)\end{array}$ & & & \\
\hline Observations & 3,108 & 3,108 & 3,108 & 3,108 \\
\hline R-squared & 0.743 & 0.743 & 0.743 & 0.743 \\
\hline Number of city & 259 & 259 & 259 & 259 \\
\hline
\end{tabular}
estimation is easy to cause the result to be biased, while Maximum Likelihood Estimation (MLE) can solve this problem effectively. First of all, cluster-robust standard errors are used to estimate the SDM of random effects, the results are as follows:

Fig. 2. Random effect of SDM model

The following are the estimated results of fixed-effect SDM:

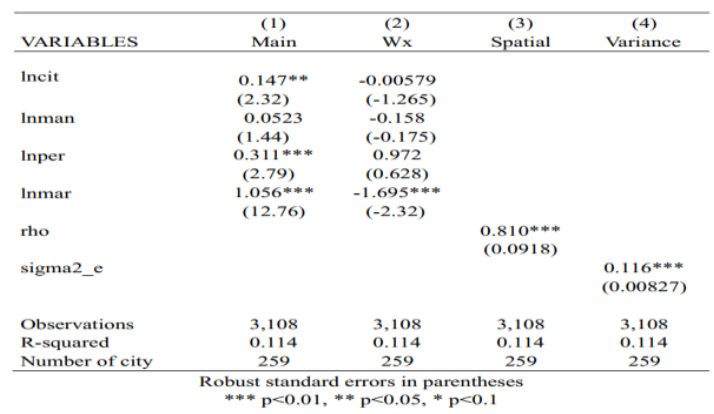

Fig. 3. Fixed effect of SDM model

Through the Hausman test of random effect and fixed effect without using robust standard errors, the original hypothesis of random effect is not rejected, so the conclusion obtained from the SDM of random effects is robust. The regression results of Table 3 show that the spatial autoregressive coefficient rho is significantly positive at the significance level of $1 \%$, indicating 
there is a significant spatial dependence in real estate investment at urban level in China, the scale of a city's real estate investment, to some extent, is affected by the level of real estate investment of the cities with similar spatial characteristics. The regression coefficients of all variables are significant at the level of $1 \%$, and the symbols are consistent with the theoretical analysis, which again proves that urban size, manufacturing scale, per capita income and market potential have significant impact on China's real estate investment. The spatial lag terms of the variables Incit and Inmar are significantly negative at the level of $1 \%$, indicating that after considering spatial factor, the expansion of urban scale and market potential will increase the intensity of market competition, when the market crowding-out effect is superior to the market scale effect, it will cause the flow of real estate investment outside big cities.

When spatial effect exists, the factors will no longer exert influence on real estate investment separately, so spatial total effect is decomposed in order to better explain the influence of each factor on the flow of real estate investment.

\begin{tabular}{lccc}
\hline \multirow{2}{*}{ VARIABLES } & $(5)$ & $(6)$ & $(7)$ \\
Incit & LR_Direct & LR_Indirect & LR_Total \\
& & & \\
Inman & $0.517^{* * * *}$ & $-0.710^{* * *}$ & -0.194 \\
& $(7.55)$ & $(-0.317)$ & $(-0.358)$ \\
Inper & $0.159^{* * *}$ & 0.0298 & $0.188^{*}$ \\
& $(2.32)$ & $(0.0114)$ & $(0.976)$ \\
Inmar & $0.648^{* * *}$ & $0.404^{* *}$ & $1.052^{* * *}$ \\
& $(1.26)$ & $(0.292)$ & $(5.243)$ \\
Observations & $0.764^{* * *}$ & -0.208 & $0.556^{* * *}$ \\
R-squared & $(9.137)$ & $(-0.142)$ & $(3.181)$ \\
Number of city & 3,108 & 3,108 & 3,108 \\
& 0.743 & 0.743 & 0.743 \\
& 259 & 259 & 259 \\
\hline \multirow{4}{*}{} & Robust standard errors in parentheses \\
& $* * * \mathrm{p}<0.01, * * \mathrm{p}<0.05,{ }^{*} \mathrm{p}<0.1$ &
\end{tabular}

Fig. 4. Direct effect, indirect effect, total effect of SDM model

It can be seen from Table 4 that the direct effects of urban population size, manufacturing scale, per capita income and market potential on real estate investment all passed the significance test of $1 \%$, showing that each factor separately has a significant positive impact on real estate investment, yet in terms of indirect effects, the scale of urban population when at the level of $5 \%$ has a significant negative effect on real estate investment, this may indicate the crowding-out effect on real estate investment as a result of the expansion of urban scale; per capita income when at the level of $5 \%$ has significant negative impact on real estate investment, this indicates that with the increase of per capita income, the demand for real estate commodities increases, which indirectly attracts the inflow of real estate investment; however, market potential has negative effect on real estate investment, not significant though. In terms of total effect, the negative effect of urban scale on real estate investment is not significant, per capita income and market potential have significant positive effect on real estate investment at the level of $1 \%$, while manufacturing scale also presents significant positive effect on real estate investment at the level of $10 \%$.

\section{CONCLUSION AND DisCUSSION}

In this paper, the indicators of China's real estate development investment are used to measure the agglomeration degree of real estate development investment in China. From the analysis of urban level in China, there are obvious differences in the development level of real estate industry in different cities. Since the adjustment by the state of industry division in 2003, the real estate industry has shown a high degree of concentration in most cities and its industrial advantages are obvious. As analyzed from the spatial change of real estate concentration, the real estate industry in coastal cities and provincial capitals maintains a high concentration every year; the development level of real estate industry is relatively high in most cities such as Beijing-Tianjin-Hebei, Yangtze River Delta, Pearl River Delta and Shandong Peninsula, while the development level of real estate industry in Chongqing, Guiyang, Kunming and other municipalities and provincial capitals in southwest China is ahead of the neighboring cities. However, in some areas with relatively slow economic growth level, the agglomeration degree of their real estate investment is relatively low, and the development level of their real estate industry is relatively backward accordingly. In recent years, with the institutional initiatives of central and local governments and the leading role of surrounding cities, the real estate industry in more and more cities has shown the advantage of agglomeration, as of 2014 , the investment in real estate development across the whole country gradually presented the trend of flowing to the surrounding areas of big cities.

In view of the spatial difference and change trend of real estate development investment, General Panel Data Model and Spatial Dubin Model are applied in this paper to verify the effects of such factors as urban population size, manufacturing scale, per capita income and market potential on the flow of real estate investment. In regions with relatively abundant initial capital, the market scale is relatively large; when the "market scale effect" prevails, it will attract more and more investors to gather here, thus forming the agglomeration development of real estate development investment; with the concentration of investment, the spatial distribution of enterprise share will deviate from the initial average distribution, the intensity of regional competition in agglomeration areas increases, and the intensity of regional competition has a negative effect on the profit rate of enterprises, when the "market crowding-out effect" prevails, real estate development investment will flow out of the agglomeration areas and to the areas with relatively low competition intensity.

The spatial distribution of capital determines that of production, and the flowing direction of real estate development investment inevitably determines the development level of regional real estate industry. If a region wants to attract the agglomeration of real estate investment, it must increase the relative size of its own market, and in the case of a given initial labor endowment, improving the capital endowment of the region becomes a viable means. While maintaining economic development of the developed regions, the central government and local governments should also increase investment in infrastructure construction and spending on education and social welfare of economically undeveloped areas, raise the cultural level and consumption level of the people in less developed areas and expand regional market scale, so as to attract the inflow of investment from real estate development enterprises. The agglomeration of real estate investment will improve the development level of regional real estate industry and drive the development of both regional related industries and national economy. Subject to the availability of data, micro influencing variables that affect investment in real estate 
development are not added to the models in this paper; in the actual decision-making of real estate development enterprises, the policies of local government system, the acquisition cost of land development as well as the cost of building materials also affect their investment decision in terms of space.

\section{REFERENCES}

[1] Marshall Alfred Principles of Economics[M].London: The Macmillan Press, 961.32-39.

[2] P. Krugman, "Increasing Returns and Economic Geography", Journal of Political Economy, 1991, 99(3):483-499.

[3] M. Fujita, Krugman, and A.Venables, 1999, The Spatial Economy: Cities, Regions, and International Trade, (Cambridge(Mass.):MIT Press).

[4] Porter Michael E Competitive Strategy[M].New York: The Free Press, 1999.165-168.

[5] Helpman E. General Purpose Technologies and Economic Growth[J]. 1998.

[6] D. Puga,"The Rise and Fall of Regional Inequalities", European Economic Review,1999,43(2):303-334.

[7] Ottaviano, G, T.Tabuchi, and J-F.Thisse, 2002, ”Agglomeration and Trade

[8] Wen Mei. Reorientation and aggregation of China's industry in the region [J]. Economics Research, 2004(2):84-94.

[9] G. Ellison, E L. Glaeser. Geographic Concentration in U.S. Manufacturing Industries: A Dartboard Approach[J]. Journal of Political Economy, 1997, 105(105):889-927.

[10] Wen Dongwei, Xian Guoming. Spatial agglomeration and export of China's manufacturing industry: an enterprise level study [J].Management World,2014,10:57-74.

[11] He Canfei, Pan Fenghua, Sun Lei.. The geographical agglomeration and formation mechanism of China's manufacturing industry [J]. Journal of Geography,2007,12:1253-1264.

[12] Luo Yon, Cao Lili. An empirical study on the trend of agglomeration degree of China's manufacturing industry [J].Economics Research,2005,08:106-115+127.

[13] Chen Jianjun, Chen Guoliang, Huang jie.. Agglomeration of producer services and its influencing factors from the perspective of new economic geography: Empirical Evidence from 222 cities in China [J].Management World,2009,04:83-95.

[14] Xu Xiaoguang,Xu wen, Zheng zunxin. Spillover effects of financia agglomeration on Economic Transformation: a case study of Shenzhen [J]. economic perspectives, 2015,11:90-97.

[15] Yu Binbin, Yang Hongxiang, Jin Gang. Can industrial agglomeration improve regional economic efficiency? -- Based on spatial econometric analysis of urban data in China [J]. Journal of zhongnan university of economics and law,2015,03:121-130.

[16] Zhang Haifeng, Yao Xianguo. Economic agglomeration, externalities and labor productivity of enterprises: evidence from Zhejiang Province [J]. Management World,2010,12:45-52.

[17] Wang Guojun, Liu Shuixin. Research on the driving effect of real estate industry to related industries [J].Economics Research,2004,08:38-47.

[18] Yuan Pengfei, Feng Lei. Economic growth, income distribution and differentiation between rich and poor -- Based on the DCGE model of real estate price rising effect [J].Economics Research,2014,09:77-90.

[19] Chen Changbing. Urbanization, real estate and macro control [J]. economic perspectives, 2015,01:29-41.

[20] Zhou Jingkui, Wu Xiaoyan. Dynamic mechanism of real estate market on regional economic growth: a case study of Beijing Tianjin Hebei metropolitan area [J]. Finance and Trade Economics,2009,02:131-135.

[21] Zhou Zhichun, Li Zheng, Mao Jie. Study on the interaction between real estate industry cycle and economic cycle -- Empirical Evidence from China [J]. Journal of Nanjing University (PHILOSOPHY, humanities, Social Sciences), 2010,06:47-57

[22] Gao Bo,Chen Jian, Zou Linhua. Regional housing price discrepancy, labor mobility and industrial upgrading [J].Economics Research,2012,01:66-79.
[1] Chen J, Zou L. Research on Optimal Public Housing Supply Range Under Domestic Demand Expansion — From the Perspective of Wealth Effect[J]. Finance \& Trade Economics, 2012.

[2] Huang Zhonghua, Wu Cifang, Du Xuejun. Real estate development investment and economic growth -- panel data analysis at the national and regional level [J]. Finance and Trade Economics,2008,08:56-60+72.

[3] Chen Shuyun, Fu Zhenqi. Analysis of the relationship between real estate investment and economic growth -- Taking 1990-2009 years time series data of Hubei Province as an example [J]. Economic system reform, 2012(2):30-35.

[4] Zhang Hong, Quan Shifan. Analysis of the impact of land supply policy on housing prices: An Empirical Study Based on Spatial Panel Econometrics [J]. Securities and futures in China, 2011(1):32-33

[5] Xu Xianchun, Jia Hai, Li Jiao, Li Junbo. The role of real estate economy in China's national economic growth $[\mathrm{J}]$. Chinese Social Sciences, 2015,01:84-101+204.

[6] Wang Chongrun, Cui Yinsheng. Crowding out effect of real estate development investment and its impact on economic growth [J]. Modern finance and Economics (Journal of Tianjin University of Finance Economics),2012,09:41-50.

[7] HARRIS, Jay C. Detergency Evaluation and Testing[J]. Soil Science, 1954, 31(77):481. 